\title{
Paisajes liminares: la concepción de la naturaleza en los territorios fronterizos
}

\section{BORDERLINE LANDSCAPES: THE CONCEPTION OF NATURE IN BORDER TERRITORIES}

\author{
PAISAGENS LIMÍTROFES: A CONCEPÇÃO DA NATUREZA NOS TERRITÓRIOS \\ FRONTEIRIÇOS
}

Ana Elvira Cervera Molina ${ }^{1}$

Para citar este artículo: Cervera Molina, A. E. (2019). Paisajes liminares: la concepción de la naturaleza en los territorios fronterizos. Perspectiva Geográfica, 24(2), 107-126. doi: 10.19053/01233769.9317
Recepción:

25 de febrero de 2019

Evaluación:

29 de mayo de 2019

Aprobación:

26 de junio de 2019

\section{Resumen}

En este texto se examina el paisaje a través del análisis de su representación y enunciación en los escenarios liminares ubicados al sureste de la Nueva España a partir de tres narraciones de viajeros que recorrieron la zona entre finales del siglo XVII y principios del XIX. El propósito es comprender cuál es la concepción de la naturaleza que sobre ellos primó, a propósito de las tres tesis del pensamiento gorgiano. A partir de este análisis, se sostiene que, en la concepción de la naturaleza, la nada y el no ser son, a partir de la idea del vacío, elementos potencialmente más creativos para la 
narración del paisaje que el todo y el ser vistos, a partir del espacio que funge como escenario de la acción del hombre.

Palabras clave: naturaleza, paisajes, sureste, Nueva España, límites, vacío.

\section{Abstract}

This article examines the landscape by analyzing its representation and enunciation in borderline settings located southeast of New Spain from three narrations of travelers who toured the area between the late 17th and early 19th centuries. The purpose is to understand which conception of nature prevailed regarding Gorgias's three theses. Building on this analysis, it is argued that in the conception of nature, "nothing" and "non-being" are, from the idea of emptiness, potentially more creative to narrate the landscape than "everything" and "being" seen from the space that serves as the scene of human action.

Keywords: Nature, landscapes, southeast, New Spain, limits, emptiness.

\section{Resumo}

Neste texto, examina-se a paisagem através da análise de sua representação e enunciação nos cenários liminares localizados ao sudeste da Nova Espanha a partir de três narrações de viajantes que percorreram a região entre o final do século XVII e o início do século XIX. O objetivo é compreender qual é a concepção da natureza que prevaleceu sobre eles em relação das três teses do pensamento georgiano. A partir dessa análise, argumenta-se que, na concepção da natureza o nada e o não-ser são, a partir da ideia de vazio, elementos potencialmente mais criativos para a narração da paisagem do que o todo e o serem vistos a partir do espaço que serve como cenário da ação do homem.

Palavras chave: Natureza, paisagens, sudeste, Nova Espanha, limites, vazio. 


\section{Introducción}

En 1827, el reverendo anglicado George Wilson Bridges inició el prefacio del volumen 1 de Los Anales de Jamaica diciendo: "De todas las diversas descripciones de la literatura, la historia ha sido considerada como la más ilustrativa, la más liberal y la más entretenida, y que la historia de nuestro propio país merece nuestra primera y mejor atención, es una proposición que no requiere argumento ni ilustración" (Bridges, 1827, p. VII). Para el escritor y clérigo anglicano, rector de parroquias en Jamaica entre 1817 y 1823 , abolicionista y fotógrafo de William Fox Talbot, la historia es una forma más de literatura descriptiva. En su visión, la historia es mucho más ilustrativa, con plasticidad discursiva, y, por supuesto, mucho más liberal y entretenida que cualquier mera enunciación ficcional asociada a lo literario.

El argumento principal en este texto se centra en el paisaje. Esto a través del análisis de su representación y enunciación en los escenarios liminares ubicados al sureste de la Nueva España a partir de las narraciones de tres viajeros que escribieron sobre la zona en tres momentos diferentes entre los siglos XVII y XIX. El propósito es comprender cuál es la concepción de la naturaleza que sobre cada uno de ellos primó. En ese sentido, podremos ver en las distintas narraciones una aparente expresión de las tres tesis del pensamiento sofista gorgiano ${ }^{2}$,

2 Gorgias de Leontinos vivió aproximadamente entre el 485 y el 375 a. de C. Vivió, según la tradición, 105 años y fue el sofista más longevo de la generación de Protágoras. No hay datos exactos de su biografía, pero se sabe que es el fundador de la retórica sistemática y autor de dos obras indispensables para la filosofía clásica: Encomio de Elena y Sobre el no ser o sobre la naturaleza. En la primera se sientan las bases de la doctrina retórica poniendo en primer plano. sobre todo, el efecto emocional que el orador consigue sobre sus escuchas. En la segunda se hace una legitimación indirecta de la retórica, que se entiende como una disciplina que se encarga de las meras opiniones y que tiene la es decir: 1) nada es; 2) si es, no puede ser cognoscible; y 3 ) si pudiera ser cognoscible, no podría ser nombrado (al menos no con contenido de verdad absoluta) (Colli, 2012, p. 49). Como apunta Colli: "Gorgias [descubre que] la palabra puede comunicar y defender cualquier experiencia, cualquier intuición, y con ello las destruye todas". Lo que vemos en los textos de Dampier, Gual y Salgari parece confirmar el hallazgo gorgiano.

Por mucho tiempo, hasta finales del siglo XIX, el espacio fue un concepto esencialmente geográfico, de tal suerte que los historiadores consideraban a la geografía como la criada de su propia disciplina (Baker, 2003, p. 16). El tiempo era tratado como un concepto esencialmente histórico, incluso hasta bien entrado el siglo XX (Baker, 2003, p. 14). Sin embargo, es necesario decir que, precisamente, en el cruce de tiempo y espacio existe el hombre, que es histórico, en relación con la naturaleza, la cual surge de una discusión dialéctica emergida a propósito de lo real y lo concreto. Bajo esta premisa en la que la naturaleza, la nada y el no ser son, es que podemos encontrar en la idea del espacio vacío (Campbell, Giovine \& Keating, 2019, p. 3) elementos potencialmente más creativos para la narración del paisaje que aquellos que se desprenden de la noción del todo. Esto es así porque el espacio vacío funge como escenario de la acción y la interpretación del hombre que le da significado y este significado, como se verá en las tres narrativas que se analizan en este artículo, es relativo, o al menos así es percibido, interpretado y narrado.

tarea de persuadir a través del discurso en vez de perseguir un conocimiento imposible del ente real. En este sentido. Gorgias parte de "la premisa de que las percepciones sensibles son privadas y, en consecuencia, diferentes personas no pueden significar lo mismo con las expresiones lingüísticas que describen tales percepciones" (Volpi, 2005, p. 846). Se espera que esta consecuencia se vea expresada en el análisis de los textos de Dampier, Gual y Salgari que se examinan en este artículo. 
Este ejercicio es una revisión de algunas formas de comprensión de conceptos e ideas de y sobre la naturaleza, aterrizados en elementos concretos de las narraciones de William Dampier (siglo XVII), Juan Bautista Gual (siglo XVIII) y Emilio Salgari (siglo XIX). En este sentido, nociones como espacio vacio, paisaje liminar y naturaleza han adquirido nuevas dimensiones de análisis que aquí se expresan a partir del examen de las fuentes de información seleccionadas, que son las que condicionan la aparición de silencios y vacíos en el paisaje narrado. Conviene aclarar, en los párrafos que siguen, las definiciones y los usos de dichos conceptos y sus relaciones en el análisis que se hace en este texto.

La idea de espacio vacío la plantean Campbell, Giovine y Keating en los términos siguientes:

Los espacios vacíos, son no solo los vacíos o la contemplación de estos, sino que son sitios que arrojan luz sobre las ansiedades y posibilidades de la modernidad. Por lo tanto, no buscamos asignar un significado específico para el vacío, sino considerar la pluralidad de significados asociados al concepto y, a su vez, lo que pueden revelar estos significados sobre el pasado y sobre sociedades e individuos contemporáneos (2019, p. 5).

Esta postura permite, en cierta forma, esquivar el debate acerca de las diferentes concepciones sobre el vacío (Bueno, 1972, p. 33) o los usos de esta idea (Latour, 1993, p. 86) y sobre las percepciones del paisaje o los subjetivismos del espacio ${ }^{3}$.

3 En relación con las percepciones del paisaje y los subjetivismos del espacio existe una extensa tradición que discute estos temas que, como se ha apuntado, son menos que ancilares al propósito de este trabajo. Se propuso, en una de
En otros términos, este artículo se circunscribe a la explicación de las estrategias que sirven a Dampier, Gual y Salgari para contar, connotar o denotar el espacio que ven, o para obviar elementos del paisaje que los otros sí aprecian. No se juzga el valor de verdad de los conceptos de vacío expresados en los textos analizados.

La noción de paisajes liminares está, claramente, compuesta por dos elementos cuyo uso concreto en este artículo se explica a continuación. El paisaje es entendido en los términos en los que, de acuerdo con Yi-Fu Tuan, se comprende desde el siglo XVII: "Una construcción mental, así como una entidad física y medible" (Tuan, 1979, p. 6). Lo liminar adquiere significado en los términos expresados por Van Gennep respecto a los ritos de paso (2008), en el sentido de ser una entrada hacia un espacio que, por vacío, es considerado nuevo.

las revisiones a este artículo, examinar la obra de autores cuyos trabajos se comentan brevemente a continuación. He aquí razones adicionales a la ya expuesta para no incluir a la mayoría de ellos en el desarrollo del argumento que se sostiene en este artículo. Bachelard, en The poetics of space (1994, original de 1958), se centra en el espacio privado y toca solo incidentalmente el tema del paisaje, razón por la cual no resulta útil para la tarea que se propone en este texto. También se sugirió incorporar a la discusión el trabajo de Bakhtin, pero debe apuntarse que dicho autor es muy claro, en sus ensayos más tardíos, al plantear el carácter incompleto e impreciso de sus conceptos sobre espacio y tiempo (Bakhtin, 1981, p. 85), es decir, Bakhtin mismo se excluiría de participar en una discusión de esta índole pues, adicionalmente, solo trata el concepto de paisaje de manera incidental. De mayor interés para este texto sería el trabajo de Philippe Descola, cuya obra es una crítica del naturalismo moderno, al que niega el carácter universal y lo sitúa solamente como una expresión singular de las formas de "objetivación del mundo y de los otros" (Descola, 2012, p. 19), de tal manera que el autor se impuso como tarea trazar la naturaleza de otros esquemas de objetivación (nótese que se centra en la objetivación, no en los subjetivismos); en cualquier caso, dado que Dampier, Gual y Salgari, cuyos textos se examinan en este artículo, pueden ser considerados modernos, se salen del ámbito de interés de Descola, más que como referentes de comparación con formas modernas de objetivación; siguiendo esa línea de pensamiento, es comprensible por qué no incluimos los interesantes conceptos de Descola en este texto. 
Es decir, el paisaje liminar es tal en tanto que el ámbito es considerado espacio vacío por quien lo describe, y así se convierte, en la mente de quien lo narra, en espacio de entrada.

\section{Sobre los mapas y el espacio}

En 2015, a propósito de la creación del discurso histórico, se publicó un texto en que se leía:

La península de Yucatán comparte con sus países vecinos, Belice y Guatemala, pero en especial con Belice, mucho más allá que una frontera geopolítica. Entre ellos comparten una historia de adscripción y dependencia, pero también de asilamiento y extranjeridad. Toda esta idea de lejanía, aislamiento y extranjeridad nace de la creación de falacias topográficas durante la época colonial que, para estos territorios, se pueden resumir en dos visiones: 1) la península como una isla, una ínsula, en donde se aprecia la negación de la prolongación continental de un territorio que, aunque fue corregida tempranamente en la cartografía europea (siglo XVI), aún hoy sigue permeando la visión de quienes habitan el territorio, y 2) el espacio amorfo, vacío y susceptible de volverse frente de expansión. Estas dos visiones se sintetizan y visibilizan en la creación de la noción de "confín" y cómo este articula dichos territorios con el poder que les da nombre (Cervera Molina, 2015, pp. 21-22).

Cuatro años después de esta publicación, con más elementos de análisis de orden filosófico que en ese entonces, cabe la duda de si es conveniente llamar a estos elementos formadores "falacias topográficas"4 o si es más pertinente llamarlos "geosímbolos" $"$, ya que se reconoce que ambos términos nacen de la capacidad del observador para argumentar a partir de "lo que no es" sobre el espacio, pero el primero lo hace mediante la relativización de la verdad geográfica, y el segundo, mediante la comprensión de la dimensión netamente simbólica de los lugares. Por tanto, ambos términos parten del ejercicio de observación y descripción de los elementos geográficos dispuestos en la naturaleza, pero el primero lo hace desde la óptica del sujeto filosófico o trascendental, mientras que el segundo lo hace desde el sujeto empírico. Al ser las fuentes primarias de la información aquí seleccionada los diarios de viaje, así como mapas y novelas, es evidente que este cambio de perspectiva de abordaje en la narración marca el devenir de la concepción histórica del concepto "geografía", así como de una de sus consecuentes ramas técnicas: la cartografía. Comúnmente se reconoce a la cartografía como una

[...] disciplina científica y técnica y como herramienta indispensable para un gran número de profesionales en el manejo de un conjunto de técnicas utilizadas para la representación gráfica y métrica de elementos espaciales y la producción de ma-

4 'Refiere un 'error' topográfico que, a fuerza de repetirse en los discursos, con el tiempo, pasa a ser tomado como una verdad geográfica que define al grupo social que habita dicho territorio o que configura los limites [imaginarios] de la escala regional" (Cervera Molina, 2015, p. 25).

5 “El geosímbolo es un marcador espacial, un signo en el espacio que refleja y forma identidad [...]. Puede definirse como un sitio, un itinerario o un espacio que por razones religiosas, políticas o culturales reviste a los ojos de ciertos pueblos y grupos étnicos una dimensión simbólica que les fortalece en su identidad" (Bonnemaison, 2004, pp. 55-56). 
pas y planos, además de modelos, diagramas e imágenes, en definitiva, todo tipo de documentación cartográfica [...] con la relevancia conocida que ha mantenido a lo largo de siglos en el contexto cultural y social (Rio Fernandes, Savério Sposito \& Trinca Fighera, 2015, p. 79).

Pero en esta definición, extraída de un diccionario de geografía aplicada, podemos observar que falta lo que Carl O. Sauer ha señalado sobre los mapas, es decir, su elocuencia. Ya que los mapas, como las novelas y las narraciones de viaje, "destruyen nuestras inhibiciones, estimulan nuestras glándulas, agitan nuestra imaginación, sueltan nuestras lenguas" (Sauer, 1956, p. 289) y son capaces de evocar, sin atender a las barreras del idioma, mundos sociales provenientes del pasado, ya sea próximo o remoto. En este sentido, los mapas nunca carecen de valor, pues en sí mismos no son buenos ni malos, tampoco ciertos o falsos. $\mathrm{Su}$ fuerza radica en su poder para evocar elementos extralingüísticos y su utilidad está mediatizada, sobre todo después del siglo XVII, por la precisión con que refieren una serie de valores económicos. Por tanto, los mapas "son una manera de concebir, articular y estructurar el mundo humano que se inclina hacia, es promovido por y ejerce una influencia sobre grupos particulares de relaciones sociales" (Harley, 2005, p. 80). Al constituir estos elementos un tipo de leguaje muy particular, el de la geografía, es posible hablar de una literatura de mapas que complementa a la literatura de viajes, sobre todo la producida durante los siglos XVIII y $\mathrm{XIX}$, y que no es precisamente cierta o falsa, sino que se basa en elementos discursivos que evalúan, miden o estructuran los objetos sobre el espacio, y su funcionalidad está dada por las relaciones dialécticas que existen entre la imagen y el poder, y por cómo estas visiones se expresan gráficamente mediante el ejercicio de la precisión milimétrica (Harley, 2005).

No podemos olvidar, sobre todo aquellos que partimos de la literatura de viajes, que en un principio el topógrafo viajaba al lado del soldado y que su principal función era trazar mapas con fines de reconocimiento: su labor consistía entonces en reflejar lo conocido con miras a la pacificación, la civilización y la explotación de las colonias ya definidas. En este mismo orden de ideas, es pertinente decir que los primeros geógrafos y los que sobrevinieron después también fueron viajeros ya que, a diferencia de los turistas, ellos viajaban con la intención de observar, conocer y registrar el mundo ya descubierto para transformarlo en territorio conocido. En la lógica militar de la conquista, los mapas se usaron para legitimar la realidad de la ocupación y dar espacialidad al ejercicio de la soberanía recién adquirida, pues ahora "El mundo podía ser grabado sobre papel" (Harley, 2005, p. 87).

A finales del siglo XVIII y durante todo el siglo XIX, momento en que la geografía se consolidaba como disciplina científica, los mapas, ya subordinados a las narraciones de viaje, adquirieron una fuerza aún mayor como documentos que legitimaban tratos, ya fueran políticos o comerciales, y la abstracción que representaban en el dibujo adquirió correspondencia física en el paisaje y la naturaleza, volviéndose entonces el rostro pujante del imperio o del naciente Estado. 


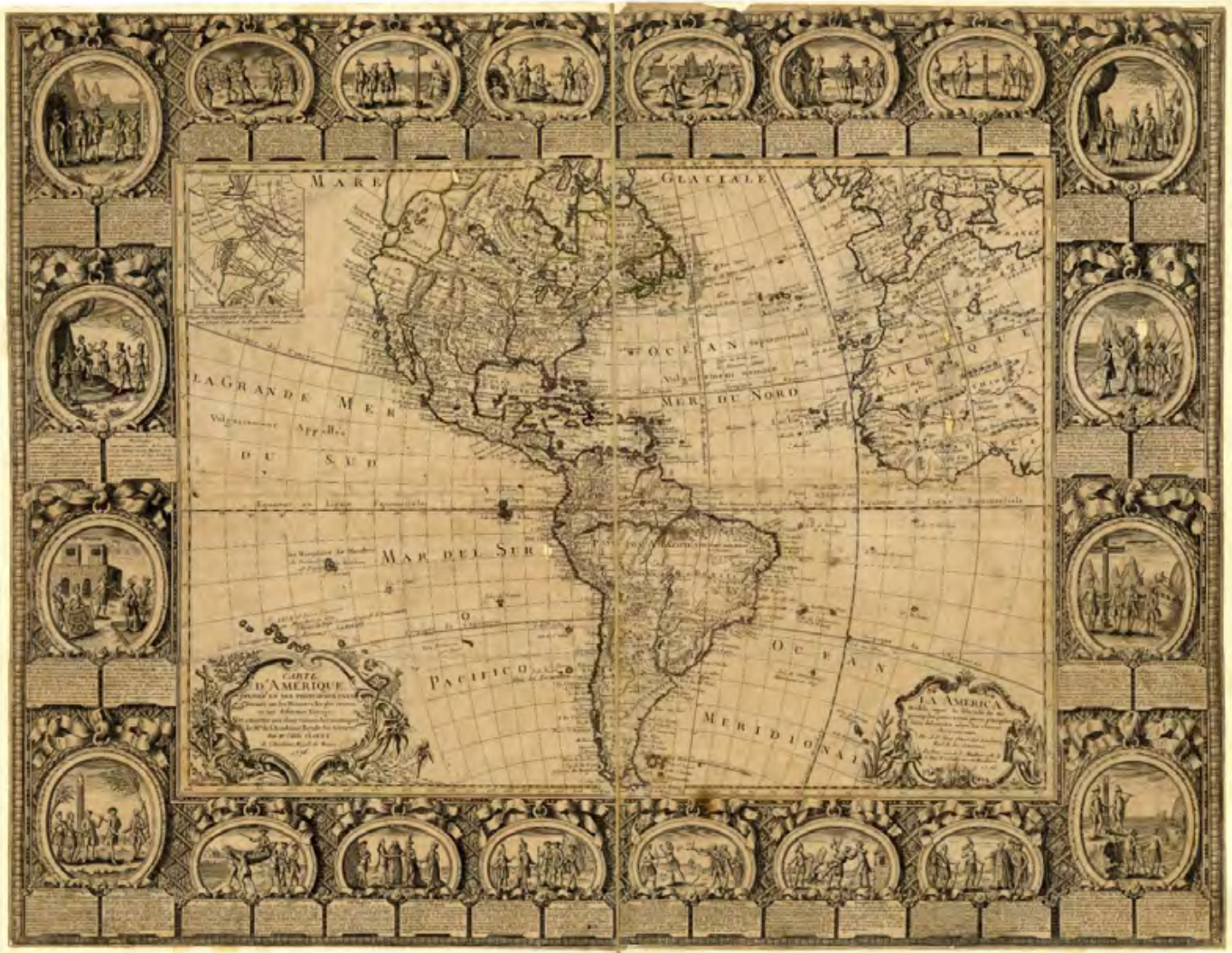

\section{FIGURA 1.}

“Cart d'Amerique divisée en ses principaux pays: Dresée sur les Mémoires les plus récents et sur différents Voyages et assujettie aux observations Astronomiques de Mrs. de l'Academie Royale des Sciences, 1776": escala hallada a partir de 5 grados de latitud $(=2,1 \mathrm{~cm})$ en el Ecuador $(=3 \mathrm{~cm})$ en el paralelo $55^{\circ}$, proyección estereográfica, coordenadas referidas al meridiano de Hierro (E 315 - E 45 / N 60 -S 50), elaborado por Mr. P’Abbé Clouet de l'Academie Royale de Rouen. Fuente: Archivo Cartográfico de Estudios Geográficos del Centro Geográfico del Ejército, Madrid.

En la Figura 1 se observa la "Cart d'Amerique divisée en ses principaux pays" hecha en la Academia Real de Ciencias de París en 1776. En ella se ilustra el continente americano. En todo el marco aparecen una serie de medallones, la gran mayoría con elementos religiosos, administrativos y naturales, que se acompañan de un breve texto, tanto en español como en francés, que explica los acontecimientos más importantes del descubrimiento y la conquista de América. Cada uno de los meda- llones que contiene esta carta viene acompañado por una escena alegórica. En el margen inferior derecho del documento se lee el título en castellano: "La América Dividida según lo dilatado de sus principales partes cuyos puntos principales están delineados sobre las últimas observaciones".

Entre las escenas escogidas para hablar de sureste novohispano (Figura 2), se selecciona exclusivamente, en la parte superior, el descubrimiento de Yucatán (ver Figura 3), y se puntualiza: 


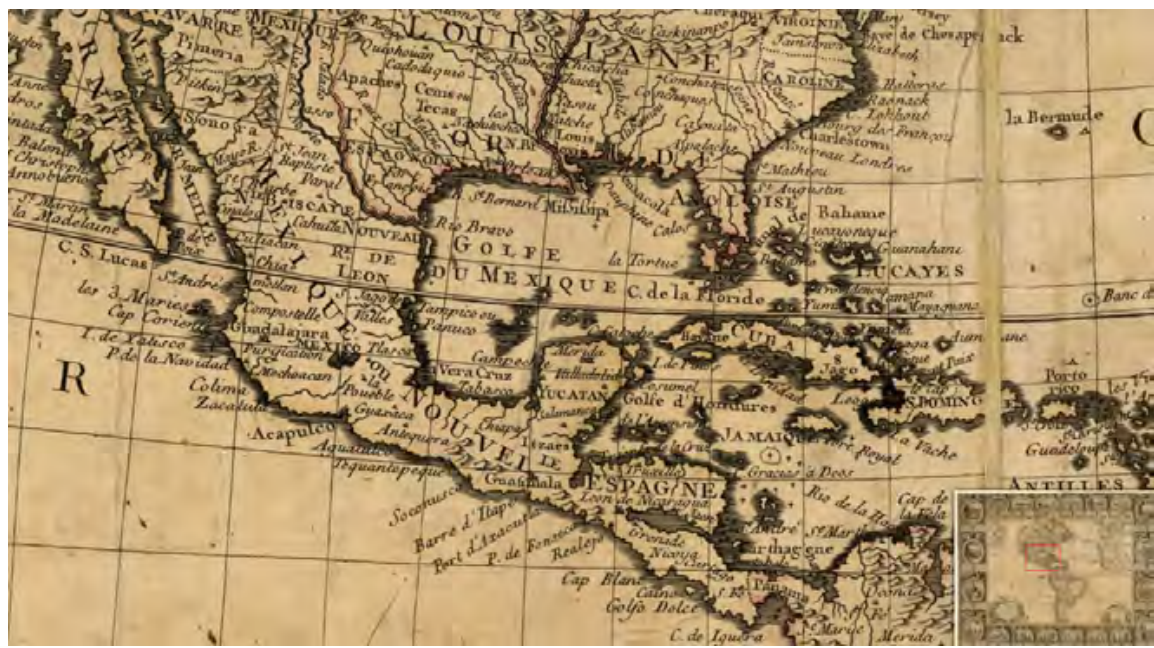

\section{FIGURA 2.}

Detalle relativo a Nueva

España de la "Cart

d'Amerique divisée en ses principaux pays".

Fuente: Archivo Cartográfico de Estudios Geográficos del Centro Geográfico del Ejército, Madrid.
Fernández de Córdoba salió de Santiago de Cuba año de 1517, con tres navíos y llevando su derrota al sur, descubrió una tierra que llamó: Yucatán, halló que los habitadores eran bienvenidos, civilizados y casas de piedra, aún se dice que hallaron maderos en forma de cruz sobre algunas sepulturas. Mérida es la capital.

Esta carta de América es claramente un documento militar que no solo sirvió para apoyar la localización e intervención de la avanzada bélica sobre América, sino que ofreció una justificación de dicha intervención, que se sustentó en la calidad moral de los habitantes originarios del sureste de la Nueva España (Figura 3), en contraposición con los trazos silenciosos del dibujo correspondientes a la zona referida, los cuales sugieren un paisaje socialmente vacío del que solo se rescatan las ciudades principales de la península de Yucatán en ese momento, es decir, Mérida y Valladolid. El resto de las poblaciones, así como sus respectivos asentamientos, no existen en el mapa, y, volviendo a las tesis gorgianas: si no existen, no pueden ser nombradas, y si no pueden ser nombradas, no pueden ser conocidas, aunque su

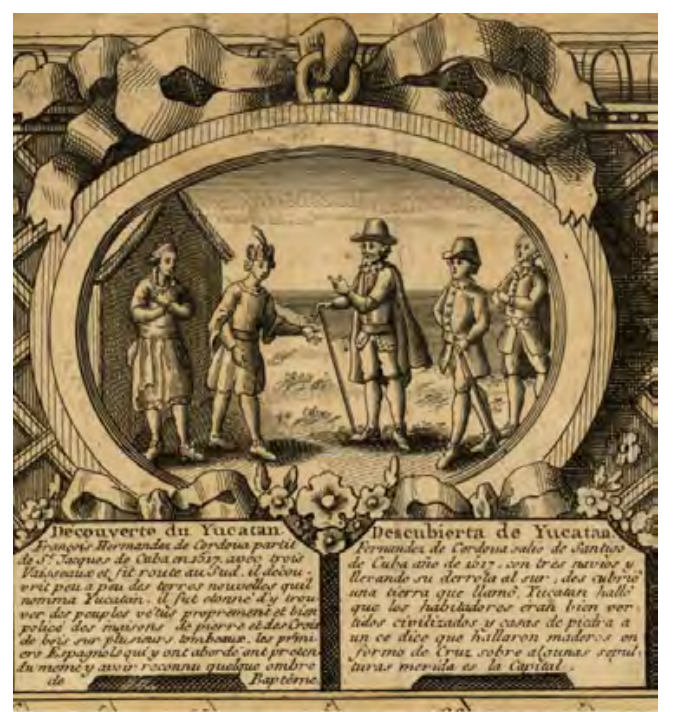

FIGURA 3.

Detalle de "Cart d'Amerique divisée en ses principaux pays".

Fuente: Archivo Cartográfico de Estudios Geográficos del Centro Geográfico del Ejército, Madrid.

potencialidad de existir quede comprendida en la concepción histórica del espacio vacío.

Por lo dicho líneas arriba, vale la pena hacerse dos preguntas, las cuales, más que retóricas, ayudan a comprender el mecanismo que permite el ejercicio de narrar y describir el paisaje: ¿qué es el espacio? y ¿cómo se articula con la documen- 
tación geográfica que representa dichos elementos cartográficos?

El concepto de espacio, desde el pensamiento geográfico, puede ser visto desde dos perspectivas filosóficas: 1) el espacio continente o receptáculo, y 2) el espacio como reflejo (Rio Fernandes et al., 2015). En el primer rubro, el del espacio como continente, se agrupan todas las conceptualizaciones que conciben al espacio como un mero soporte en el que se localizan elementos y relaciones, pues, como su nombre lo indica, el espacio solo es capaz de contener objetos (Hiernaux \& Lindón, 1993). Bajo esta lógica, en el espacio geográfico solo es posible hablar de relaciones unidireccionales que nulifican cualquier influencia extralingüística sobre los elementos; cuando mucho, se pueden apuntar relaciones simplificables entre ellos (como, por ejemplo, la noción de distancia), que se vuelven medibles en cuanto a la precisión de la valoración del tiempo y el costo invertidos para alcanzar un punto determinado.

Para el caso específico del sureste de la Nueva España, un ejemplo preciso de esta concepción del espacio geográfico la encontramos en el diario de reconocimiento de 1792 del capitán español Juan Bautista Gual, en el cual relata su viaje a los establecimientos ingleses de la parte oriental del Yucatán y sus inmediaciones. En dicho diario se lee:

Martes 24. Continué subiendo a Roaring Creek con grandísimo trabajo de la tropa, la cual tenía que arrastrar, y casi con algún riesgo, las embarcaciones por los raudales y llegué al medio día al rancho de Mr. Catto que era cuatro millas de la boca de dicho estero (Folio 49, Diario de
Bautista Gual, Archivo General de Simancas $[\mathrm{AGS}])$.

En esta narración, se observa que el espacio solo es capaz de contener objetos en un sentido empírico, pues solo se refiere la relación de distancia existente entre uno y otro objeto de interés económico o político. Aquí se observa una visión economicista del espacio, en tanto que este resulta "un receptáculo (o un plano homogéneo) en el que se implantan las relaciones económicas" (Hiernaux \& Lindón, 1993, p. 91) entre dos naciones en conflicto, en este caso, España e Inglaterra. Por consecuencia, el paisaje aquí no existe, pues no representa una imagen completa del territorio o la naturaleza, sino que ofrece visiones fragmentarias que declaran la existencia de objetos u objetivos de interés económico.

En el segundo rubro referido, en el del espacio como reflejo, de nueva cuenta el espacio vuelve a ser un elemento pasivo, pero ahora solo se le considera en la medida en que es espejo de la sociedad y de las relaciones sociales que lo atraviesan. En este sentido, el paisaje no se vuelve un elemento que se modifica en el largo plazo, como veremos más adelante, ni tampoco una imagen fragmentada del territorio y la naturaleza, como vimos en el caso del espacio continente, sino se vuelve un escenario en el que todo cambio social se refleja inmediatamente. Para dar un ejemplo más puntual de esto me remitiré a una de las descripciones más famosas de William Dampier, hecha a propósito del territorio de Los Petenes ${ }^{6}$. En su texto Dos viajes a Campe-

6 Con respecto al territorio que describe Dampier, vale la pena hacer ciertas aclaraciones. El nombre correcto de este particular paisaje es "Los Petenes", pues corresponde a la biosfera ubicada en la costa norte de Campeche que recientemente (el 16 de abril de 2019) se incendió. 
che, publicado en 1699, Dampier, el pirata botánico de Campeche, dice:

Pero cualquiera que fuese su finalidad en un principio, ahora se ha dejado de lado por completo, ya que no se las utiliza, ni hay habitantes cerca del lugar.

Entre El Monte y Cabo Condecedo, cerca del mar, hay multitud de pequeñas manchas de manglares, que a la distancia parecen como islas; pero al acercarse, cuando aparecen otros árboles más bajos, semejan un terreno roto y deshilachado, y al final la tierra se presenta muy llana a la vista (Dampier, 2004, p. 55).

$[\ldots]$

No es cosa nueva que en estas partes boscosas de América huyan pueblos enteros de indios de una sentada y se establezcan en selvas no frecuentadas para disfrutar de su libertad; si por accidente son descubiertos, se mudarán de nuevo, lo cual harán fácilmente pues sus enseres domésticos son muy pocos, además de sus hamacas y calabazas (Dampier, 2004, pp. 221-223).

Una advertencia muy similar a la de Dampier con respecto a los indígenas nativos mayas y su íntima relación con el territorio podemos encontrarla,

En consecuencia, es incorrecto referir este territorio indistintamente como el Petén o el Petén campechano, pues no refiere al mismo espacio. El primero, el Petén, refiere un departamento de Guatemala, y el segundo, el Petén campechano, es la región del municipio de Calakmul que colinda justamente con la frontera guatemalteca del departamento del Petén. Aunque petenes (en minúscula) se refiere a los microsistemas ecológicos de humedales que se encuentran en toda la plataforma peninsular yucateca, lo cual incluye parte de Guatemala y Belice, además de La Florida y Cuba, Los Petenes (con mayúsculas y con el artículo Los) solo refiere la zona natural protegida que abarca la costa norte de Campeche. casi un siglo después, en el diario de reconocimiento del ya mencionado capitán Juan Bautista Gual, pero su puntualización no se hace ahora sobre la población indígena local, sino sobre los ingleses arranchados fuera de los límites establecidos por la Convención de Londres de 1786. En 1792, Bautista Gual escribió:

A estos no los acompaño a la Boca del Valis para entregarlos a los Magistrados como previenen las Instrucciones del Señor Capitán General, porque tengo vehementes sospechas de que hay muchos más infractores a quienes no encontraría si yo diese tiempo a que ellos supiesen que me hallo reconociendo estos cayos y entonces no me sería dable documentar tantas infracciones como juzgo están cometiendo que es el principal objeto de su señoría según se sirvió explicarme de palabra (Folio 16, Diario de Bautista Gual, AGS).

Lo que vemos en los ejemplos no solo son dos formas de abordar el pensamiento geográfico que conviven y perviven en el tiempo, sino el establecimiento de paradigmas geográficos que tuvieron, por consecuencia, su aplicación en la cartografía, en donde los diversos grupos étnicos que habitan las zonas descritas estuvieron condenados al "no ser" o al desvanecimiento progresivo de su figura sobre el territorio.

\section{Sobre el espacio continente y su enunciación en el mapa}

En cuanto al espacio continente, este puede ser observado desde dos perspectivas filosóficas distintas, la empírica y la idealista, aunque cabe aclarar 
que ambas posturas tienen como punto de convergencia la idea de que los objetos del mundo real pueden existir fuera del espacio. Según Hiernaux y Lindón, la perspectiva empírica deviene directamente del pensamiento aristotélico, encuentra su máximo punto de afirmación con Newton y pasan por un proceso de redefinición con Descartes. En esta postura el espacio refiere un concepto absoluto en el que no cabe la posibilidad del vacío, pues "Para Aristóteles el espacio es un límite inmóvil que inmediatamente envuelve a un cuerpo" (Hiernaux \& Lindón, 1993, p. 93).

Un ejemplo de la aplicación de la perspectiva filosófica empírica a la cartografía correspondiente a la zona liminar del sureste de la Nueva España la encontramos en el mapa "Carta esférica que comprehende una parte dela costa de Yucatán, Mosquitos, y Honduras. Construida de orden del Exmo. Sor. Dn. Juan de Araoz" de 1801 (Figura 4). En ella vemos el dibujo de un solo segmento geográfico, puesto que abarca la costa oriental de América Central, desde la laguna del Norte hasta el río Tortuga, incluyendo islas y archipiélagos adyacentes. En sí misma, la carta es toda una oda a la precisión, pues presenta márgenes graduados y bastantes escalas de corrección de las coordenadas que en un principio fueron dadas. También presenta una delimitación de cotos de profundidad, calidad de fondos y fondeaderos en concordancia con los índices dados al margen. Además, presenta una relación de las montañas más significativas, cuyo perfil topográfico se plasma en la esquina superior del documento (Figura 5). En la parte inferior derecha, presenta cuatro planos: de la ciudad de Trujillo, del cabo del Triunfo de la Cruz, del puerto de la Granada, y de los fondeaderos de la Utila y de los Cochinos. Pero lo realmente interesante de esta carta es la nota explicativa que aparece a la izquierda, en donde se da información sobre los documentos en los que se ha basado el comandante Juan de Araoz para la elaboración del mapa y se advierte que toda esta información ha sido verificada por los capitanes de fragatas y demás prácti$\cos$ (Figura 6).

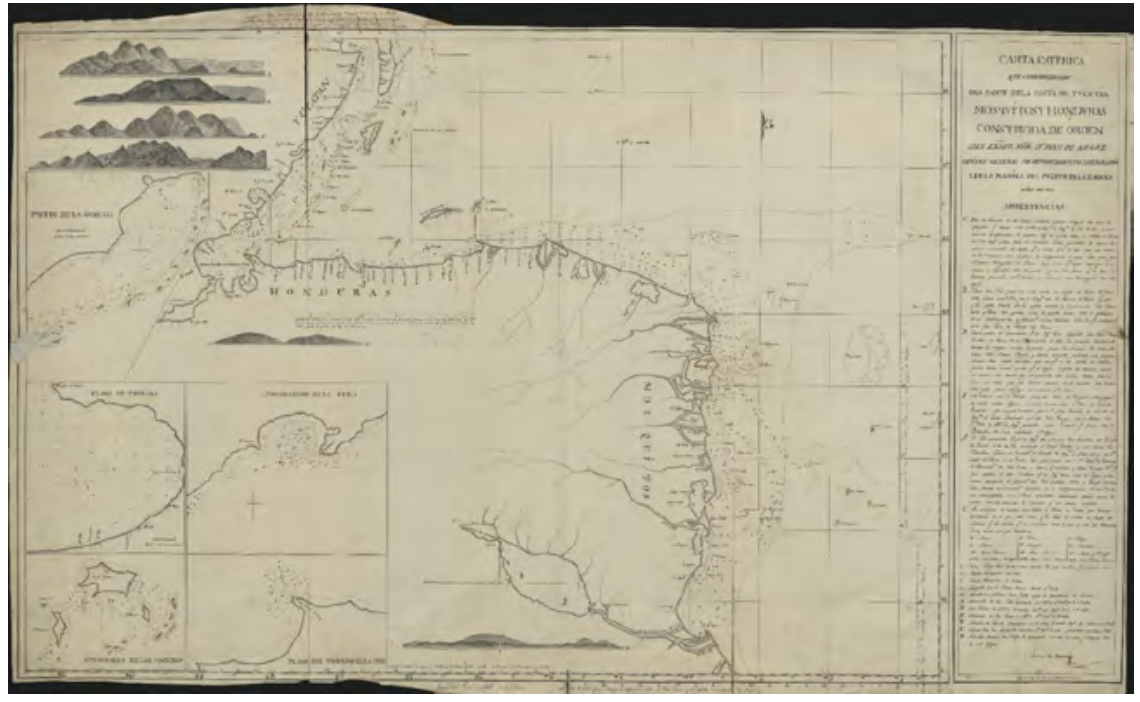

FIGURA 4.

“Carta esférica que

comprehende una parte de la costa de Yucatán, Mosquitos y Honduras. Construida de orden del Exmo. Sor. Dn. Juan de Araoz; por el $2^{\circ}$ Piloto dela Real Armada Dn. Manuel Guim de Torres", 1801, escala $1: 1.500 .000$ Fuente: Archivo del Museo Naval de Madrid. 


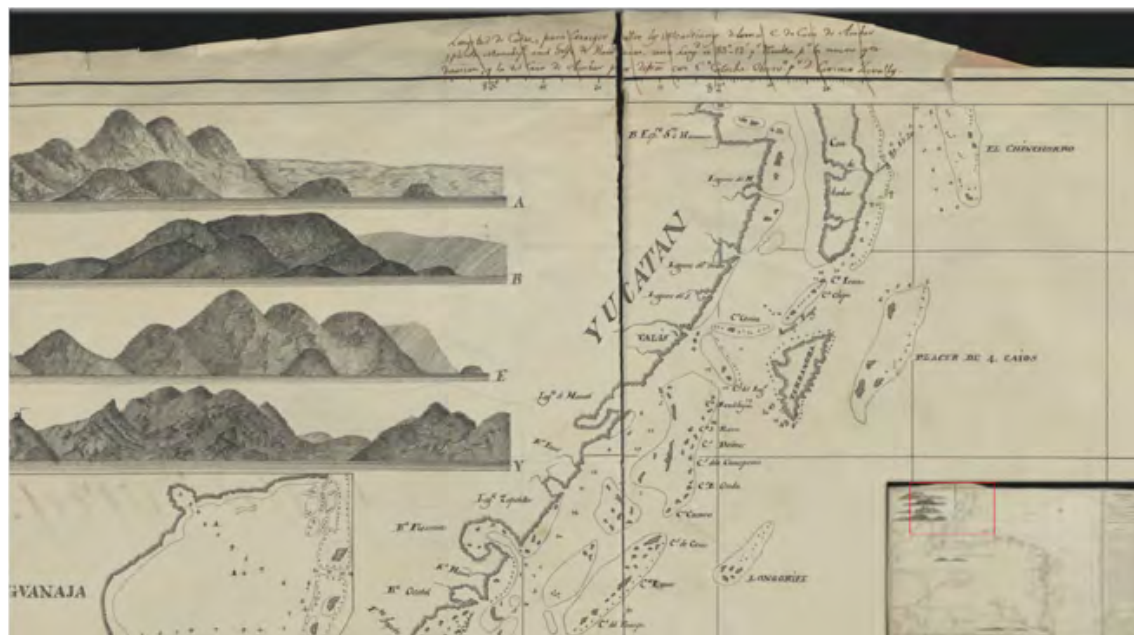

FIGURA 5.

Detalle relativo a la "Carta esférica".

Fuente: Archivo del Museo Naval de Madrid.

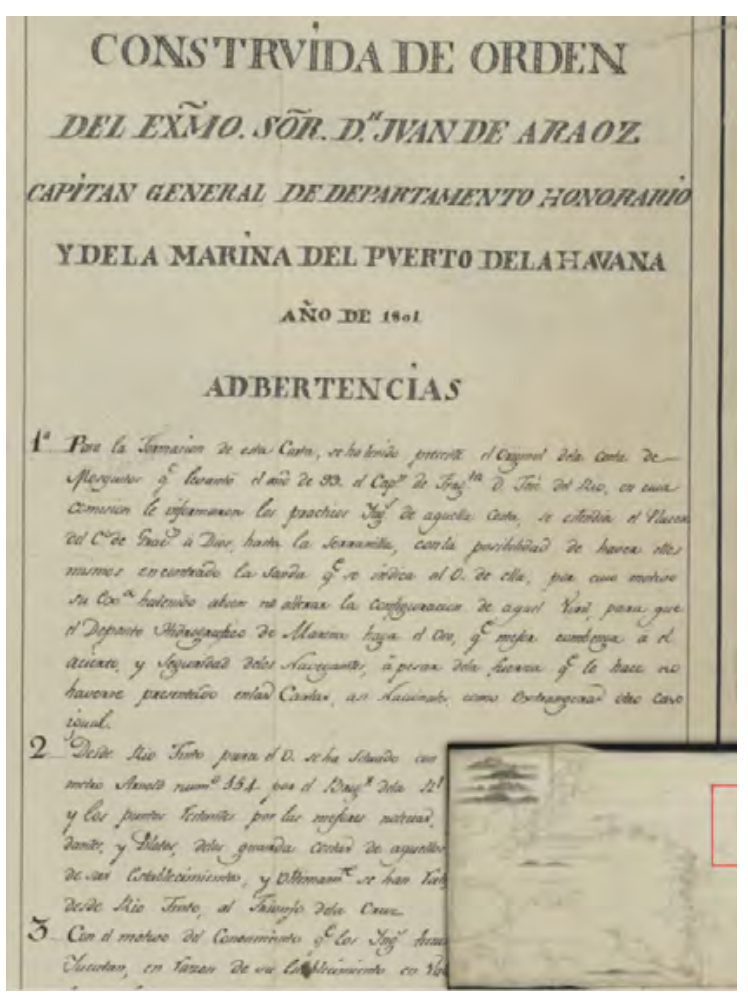

FIGURA 6.

Detalle de "Carta esférica".

Fuente: Archivo del Museo Naval de Madrid.

Dos elementos son visibles en el discurso científico de corte empirista que ofrece esta carta: 1) la ciencia de la medida y el orden, y 2) el principio de clasificación o tabulación ordenada (Harley, 2005). En este sentido, se observa la uniformidad del trazo, así como la saturación dada por el uso de la corrección de coordenadas y el margen graduado. Aquí no hay posibilidad de vacío, aunque sí se observa el uso del espacio en blanco. En cuanto a las relaciones externas al documento, vale la pena aclarar que el comandante de la Marina de la Habana, don Juan de Araoz, peleó, junto con el capitán Juan Bautista Gual, en la Batalla del Cayo St. George de 1798 bajo las órdenes del gobernador y capitán general de Yucatán, Arturo O’Neil de Tyrone y O'Kelly, y que la elaboración de este mapa es apenas tres años posterior a la ya mencionada malograda batalla, la cual se tomó como parteaguas simbólico e histórico para la apropiación del territorio correspondiente a Honduras Británica por parte de Inglaterra.

En cuanto a la perspectiva idealista, destaca la idea de Leibnitz de que el espacio es un orden mental en el que los objetos coexisten y en donde cabe la posibilidad del vacío, ya que "el espacio viene a constituirse en un sistema de relaciones, que existen independientemente de los individuos" (Hiernaux \& Lindón, 1993, p. 94). Un claro ejemplo 
para comprender esta postura la encontramos en el mapa "Costa de Honduras y Mosquitos. Arreglado por los Quarterones del Capitan Rosas" (Figura 7), que fue elaborado durante el siglo XVIII, pero del que no tenemos autor ni fecha exacta. Este mapa de la costa refleja la zona en conflicto del Walix que el capitán Bautista Gual recorre durante su visita a los establecimientos ingleses entre febrero y julio de 1792, justo en el momento posterior en el que el coronel inglés Marcus Despard es destituido de su cargo como superintendente, al ser acusado de excesivo trato amistoso con las autoridades españolas, para ser sustituido por Peter Hunter, quien se mantuvo en el cargo hasta el estallido local de hostilidades en 1798.

En este mapa, el vacío visible existe tierra adentro, mas no en el escenario marítimo, el cual goza de una saturación en color aguamarina y del trazo de meridanos. El bloque geográfico descrito aquí abarca desde cabo Catoche hasta el río Niawa, con un solo acento teñido de rojo en donde se apunta una fortificación inglesa próxima a río Walix (Figura 8). El dibujo de esta geografía interior apenas esbozada establece una gran paradoja con relación a la perspectiva idealista, pues en ella los espacios socialmente vacíos parecieran no tener consecuencias sociales y mucho menos políticas, pero lo cierto es que el mapa inaugura un frente de expansión, un paisaje liminar, al mostrar la zona como una serie de escenarios abiertos en donde prima el silencio toponímico, es decir, en donde predomina el no ser que no puede ser nombrado y, por tanto, no puede ser conocido, pero que potencialmente existe.

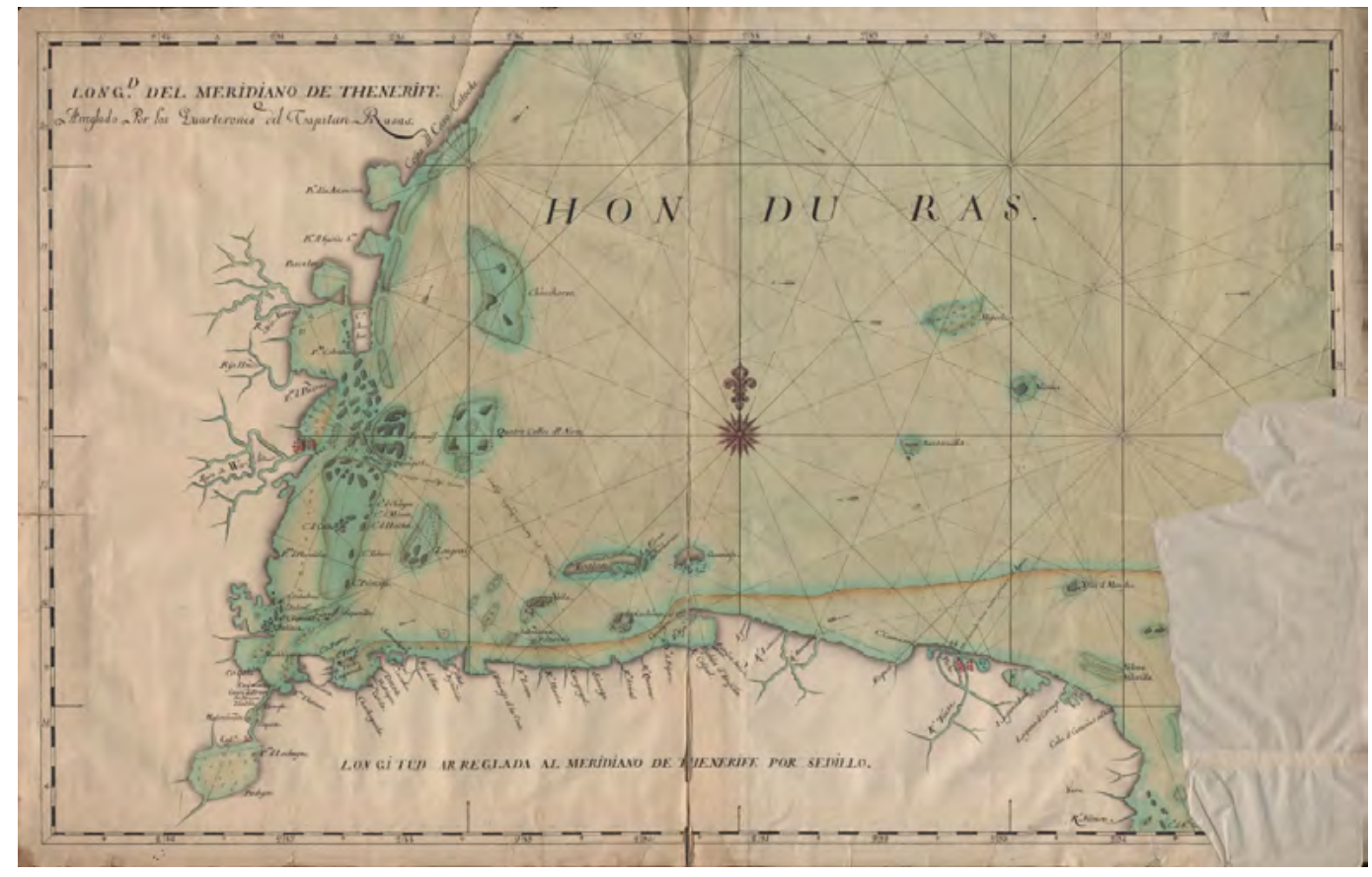

FIGURA 7.

"Costa de Honduras y Mosquitos. Arreglado por los Quarterones del Capitan Rosas": ca. siglo XVIII, escala 1:1.340.000. Fuente: Archivo del Museo Naval de Madrid. 


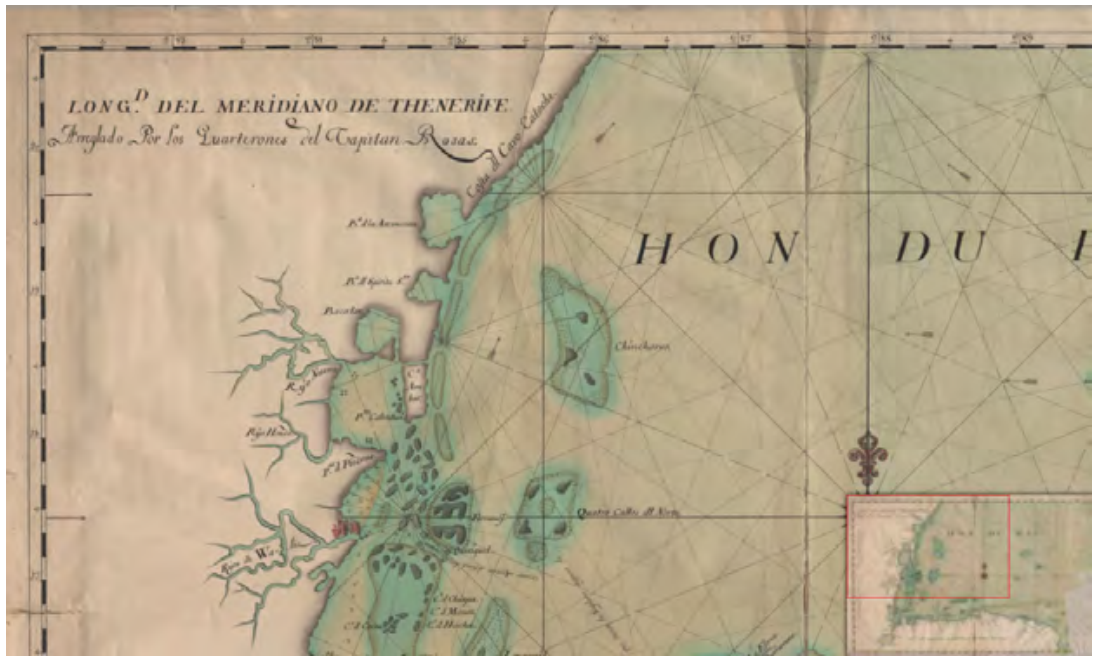

\section{FIGURA 8.}

Detalle de "Costa de Honduras y Mosquitos".

Fuente: Archivo del Museo Naval de Madrid.
Ya para el siglo XIX, la literatura de mapas, de la mano de la literatura de viajes y las novelas de aventuras, ofrecerá visiones más elaboradas del territorio en donde se pueden observar, de la mano de las narraciones y descripciones del paisaje, visiones más complejas del espacio y la naturaleza en donde el espacio puede ser observado como "un conjunto indisoluble, solidario y también contradictorio, de sistemas de objetos y sistemas de acciones, no considerados aisladamente, sino como el contexto único en el que se realiza la historia" (Santos, 1996, p. 54).

\section{Sobre el paisaje y la}

\section{naturaleza}

A principios del siglo XIX, las novelas de aventuras no son ajenas a los abordajes geográficos del espacio continente que se debaten entre la perspectiva filosófica empírica y la idealista, pero su concepción y confección ya no surge desde el mapa o desde la descripción geográfica del diario de visita, sino desde las narraciones del paisaje vistas a partir de un tropo literario que se alimenta de estas fuentes. En la novela de Emilio Salgari La reina de los caribes, publicada en 1901, el corsario negro, protagonista masculino del relato, llega gravemente herido al mar Caribe y entra a las costas yucatecas navegando desde la costa de Nicaragua. Mirando tierra firme desde el barco, el protagonista afirma:

Avistado el cabo, la veloz nave, después de una rápida aparición en la vasta laguna de Caratasca para ver si había aparecido alguna escuadra filibustera, se lanzó a toda vela en el golfo de Honduras, inmensa ensenada de forma triangular que baña las costas de Yucatán y de Belice por Septentrión, de Guatemala al Oeste y de Honduras al Sur.

En el momento en que la nave, después de haber doblado el cabo Camarón, bogaba hacia la isla Bonaca, el Corsario Negro, ayudado por Yara y Carmaux, subía por primera vez sobre cubierta. [...]

Permaneció algunos minutos agarrado a la borda, sin buscar el apoyo de Yara ni de Carmaux, y se sentó, o por mejor decir, se dejó caer junto a una de las dos piezas de artillería. 
Era un espléndido atardecer, uno de esos atardeceres que no se ven más que en las orillas del Mediterráneo o en el golfo de México.

El sol caía entre una inmensa nube de color de fuego que se reflejaba en la tranquila superficie del mar.

La brisa que soplaba de tierra llevaba hasta el puente de la nave el penetrante perfume de los cedros, ya en flor, la cristalina diafanidad de la atmósfera permitía distinguir con nitidez maravillosa las ya lejanas costas de Honduras.

No se veía ni una vela en el horizonte, ni un punto negro que indicara la presencia de cualquier chalupa.

El Rayo, empujado por la brisa, corría veloz sobre el agua, casi tranquila y transparente, grácilmente inclinado hacia estribor, y dejando a popa una blanca estría que se prolongaba indefinidamente: parecía un inmenso halcón rasando la superficie del mar (Salgari, 2004, cap. X).

En la narración de Salgari, es el paisaje tropical, ubicado durante el siglo XVII, el que se evoca emotivamente en las costas yucatecas y hondureñas. Narrado como si fuera observado durante la época dorada de la piratería en el Caribe, este paisaje tropical ya no es visto con los ojos de la ciencia ni de la precisión matemática, sino a través de los ojos de la emoción, la cual no pretende retraerse ni ocultarse en el relato. La única constante que predomina en la narración literaria del siglo XIX de esos tiempos remotos de los perros del mar isabelinos es el imaginario de que las costas del Caribe continental son un territorio despoblado que es de uso corriente por proscritos nómadas.

Con respecto al paisaje, Joan Nogué afirma que este "es el resultado de una transformación colectiva de la naturaleza; es la proyección cultural de una sociedad en un espacio determinado; es el rostro del territorio" (Nogué, 2012, p. 129). Por tanto, el paisaje es un dinámico código de símbolos que es capaz de asimilar, con el tiempo, importantes modificaciones territoriales, siempre y cuando estas no sean violentas o demasiado rápidas. En este sentido, la observación de la modificación del paisaje y la concepción de la naturaleza son fenómenos que solo son visibles en los análisis de larga duración. En ellos, se puede observar cómo elementos nuevos se insertan gradualmente en las formas de mirar de las personas (Nogué, 2012), creando así paisajes de referencia que dialogan con la legalidad y la visibilidad, en especial, en los contextos liminares que darán paso a la articulación de las fronteras territoriales.

Con respeto a los paisajes liminares, es pertinente decir que el concepto "liminaridad" fue acuñado por el sociólogo francés Arnold Van Gennep en su libro de 1909 Les rites de passage. Este concepto refería la separación de una posición social para incorporarse a una nueva, que ocurre durante los rituales de iniciación y los ritos de paso (Van Gennep, 2008). Sin embargo, en 1967 Victor Turner, en su libro The Forest of Symbols, recupera este término para referir aquello que está entre lo uno y lo otro, es decir, el término se aplica para aludir a los procesos de transición, aunque estos no estén ritualizados (Turner, 1980). En el presente trabajo, el concepto "paisajes liminares" se utiliza para referir la transición de un estado no reconocido del territorio a uno reconocido en donde la 
frontera, entendida como espacio de enunciación, se convierte en el escenario en donde se observan constantemente las tres características básicas de la liminaridad derivadas de las antiguas tesis gorgianas: 1) ambigüedad en la comprensión del yo (nada es); 2) invisibilidad estructural (si es, no puede ser nombrado); y 3) carencia casi total de atributos sociales (si no puede ser nombrado, no puede ser cognoscible). Por consiguiente, la liminaridad es una condición inherente al vacío, y este, a su vez, es parte fundacional de la frontera, entendida como límite territorial.

Como ya vimos, al paisaje pocas veces lo encontraremos en la literatura de mapas. En la visión espacial que recupera la cartografía, su dibujo es meramente evocativo y dialoga entre el paradigma empírico y el idealista del espacio continente. Sin embargo, al paisaje lo encontraremos en la narración, en especial a través del ejercicio de la descripción del espacio como reflejo o del espacio entendido como un complicado sistema de relaciones que es de carácter histórico. Esta narración se lleva a cabo a través del bien llamado ejercicio del "realismo etnográfico" del cronista, el cual está plagado de geosímbolos, o de la emotiva pluma del novelista de aventuras, que está plagada de tropos. Por tanto, todos los paisajes son inventados, pues en ellos se buscan modelos, patrones de referencia o marcadores identitarios que se acerquen a los que el observador ya tiene en su inconsciente colectivo, el cual es producto de siglos de repeticiones constantes de imágenes evocadas. En consecuencia, el proceso normal de integración de los elementos naturales en el paisaje es lento y paulatino, pero en la liminaridad este es un proceso bastante más complejo, pues refiere la integración de elementos que parten de una lógica discursiva que tiende al vacío y al vaciamiento. En los paisajes liminares lo que se intenta integrar al discurso son territorios aparentemente fracturados, desdibujados o apenas configurados en los que prima el paisaje itinerante y nómada, y su carácter inasible deviene de la narración, en donde los geosímbolos son repetitivos y generan una desagradable sensación de confusión, desconcierto y desamparo, pero una sobrecogedora contemplación de la naturaleza. Estamos entonces frente al indómito desierto.

El desierto como espacio geográfico es comúnmente entendido a partir de su clima, es decir, del clima desértico, pero lo cierto es que en un primer sentido el término califica "A espacios desprovistos de presencia humana, cualesquiera que sea sus situaciones climáticas" (Giménez \& Héau Lambert, 2007, pp. 8-9). Desde la geografía, la condicionante para concebir un desierto y su paisaje, el paisaje desértico, es la accesibilidad al agua. En este sentido, el paisaje desértico está más marcado por el imaginario de lo sobrecogedor y lo desordenado que por las condiciones del clima y la topografía. En la liminaridad del espacio desierto, prima la trashumancia y el nomadismo. Lo que vemos entonces no son una serie de asentamientos urbanos, sino circuitos de asentamientos temporales que se mueven antes que las autoridades lleguen a confrontarlos, expulsarlos y nulificarlos. En este sentido, el paisaje desierto es el paisaje liminar que funciona como sinónimo de territorio vacío y como percepción visual o sensorial de una porción del territorio que se hace extensiva a todo el ambiente natural. "Según los geógrafos culturales, la función del paisaje es la condensación metonímica del territorio no visible en su totalidad, según el conocido mecanismo retórico de la parte por el todo" (Giménez \& Héau Lambert, 2007, p. 27). Es en este punto que las tesis gorgianas em- 
piezan a tener aún más eco en esta aproximación al mostrarse como falsas en un sentido filosófico, pues cuando la nada es, puede ser cognoscible $y$, por tanto, puede ser nombrado, pero solo puede hacerse en términos negativos, es decir, a partir de lo que no hay o de la ausencia.

Entonces el paisaje liminar existe y lo hace dos veces, como diría Bourdieu, en la realidad objetiva (paisaje de referencia) y en la representación (paisaje imaginado), pero no es posible percibirlo sensorialmente, sino desde el trasfondo de nuestras representaciones sociales (Giménez \& Héau Lambert, 2007). De este modo, encontramos en las narraciones no solo de William Dampier o Juan Bautista Gual, sino de gran parte de los comisionados de las visitas a los establecimientos ingleses del Walix y de algunos viajeros que recorrieron la parte más septentrional de la Nueva España, ciertas visiones dominantes de la naturaleza que van a alimentar constantemente la literatura de aventuras, que evocará posteriormente estos paisajes de forma emotiva. Las visiones aquí citadas contemplan el espacio como desolado, como tierras con climas extremosos, como lugares inhóspitos e intransitables, como los confines habitados por los enemigos de Dios y el Rey, como territorios vacíos, pues no están habitados por hombres civilizados, como una región devaluada, como un lugar de castigo, y, una de las visiones más poderosas metafóricamente, como un lugar en que la selva se devora a sí misma constantemente.

\section{Conclusiones}

Para concluir, nos queda pendiente una pregunta: ¿cómo leer estos paisajes desiertos y liminares considerando que muchos de ellos son narrados como vacíos, desocupados, aparentemente libres, como tierra de nadie y como territorios sin rumbo? La respuesta es: desde el dilema gorgiano aplicado a lo inacabado, que sugiere el concepto de liminaridad. Estos paisajes son, pero son indeterminados, pues no son territorios domesticados, sus límites son imprecisos, sus usos, inciertos, expectantes, $y$, por tanto, constituyen una mezcla inacabada entre lo que ha dejado de ser y lo que no se sabe si será. Solo existen en el vacío. Son potencialidad creativa, pero nunca certeza enunciativa.

Para el paisaje liminar, el vacío no es solo una potencialidad en el espacio inaugurada por el paradigma filosófico idealista o una particularidad geosimbólica que goza de una parte poética, sino que también tiene un componente de instrumentalidad. De entrada, es pertinente comprender que esta es una forma de espacialidad que se construye desde afuera, pues no forma parte directa de los territorios vividos, los cuales se mueven, al menos en la época colonial y de posterior configuración de la nación, dentro del paradigma empírico del espacio absoluto. El vacío, al ser un elemento extralingüístico, tiene la particularidad de extenderse hacia ámbitos instrumentales concretos. En ese sentido, tenemos diferentes tipos: vacío de relaciones sociales; vacío de infraestructura; vacío de soberanía, en donde las concesiones forestales, como las que menciona Bautista Gual y las que favorecieron el asentamiento de ingleses en las inmediaciones del río Walix, constituyen una forma de ejercicio de visibilización de la soberanía española que, sin embargo, se desdibuja constantemente por la transgresión repetida de los acuerdos. También existe el vacío de población que se presenta por una baja densidad demográfica, o aumentos y descensos de población favorecidos por la colonización induci- 
da, los cuales buscan contrarrestar la autonomía local de los asentamientos (Macías Zapata, 2004).

Pero vale la pena aclarar que aquí no solo se hace referencia al vacío en relación con el paradigma idealista, aunque este sea el único que permite su existencia, sino también en relación con la teoría de los silencios cartográficos de Harley. A partir de esta teoría, volvemos al mapa y a la documentación cartográfica sobre la que empezó la reflexión de este texto. En su obra, Harley apunta que "Al evaluar los silencios debemos estar conscientes no sólo de los límites geográficos del conocimiento, sino también de las limitaciones tecnológicas de la representación, así como de los silencios en el registro de la historia debido a la destrucción de pruebas" (Harley, 2005, p. 115). En consonancia, vale pena decir que, con excepción del espacio en blanco, todos los silencios son políticos, y, por tanto, pueden ser considerados como declaraciones positivas de interés y no solo como brechas negativas en el flujo del lenguaje. En el paisaje liminar sí vemos la aparición de los recursos naturales con valor comercial, así como sus modos de explotación.

Pero la estandarización del discurso científico enfocado en medir, ordenar y clasificar genera silencios de uniformidad que también son extensivos a las áreas liminares, y en ellos vemos elementos cada vez más abstractos, como la medición en varas cuadradas que usan los militares en los asentamientos ingleses para definir los límites de las huertas, y menos diferenciados en su modo de representación, como el establecimiento de un mismo sistema de medición y clasificación estándar, casi siempre de carácter biunívoco: cultivado-no cultivado, dentro-fuera de la normatividad, legales o ilegales. Es entonces que la diversidad de los paisajes desiertos tiende a desaparecer para dar paso a un estereotipo, un tropo literario, el cual resulta más fácil de explicar en términos de difusión de los geosímbolos de otras realidades apenas comprendidas derivadas del dilema gorgiano. 


\section{Bibliografía}

\section{Fuentes de archivo}

Archivo Cartográfico de Estudios Geográficos del Centro Geográfico del Ejército, Madrid.

Archivo General de Simancas (AGS).

Archivo del Museo Naval de Madrid.

\section{Referencias}

Bueno, G. (1972). Ensayos materialistas. Madrid: Taurus.

Baker, A. R. H. (2003). Geography and History: Bridging the Divide. Cambridge: Cambridge University Press.

Bakhtin, M. M. (1981). The Dialogic Imagination. Four Essays. Austin: Texas University Press.

Bonnemaison, J. (2004). La géographie culturelle. París: Editions du C.T.H.S.

Bridges, G. W. (1827). The Annals of Jamaica. Vol. 1. London: John Murray. Recuperado de http://archive.org/details/annalsofjamaica01 briduoft.

Campbell, C. J., Giovine, A. \& Keating, J. (Eds.) (2019). Empty Spaces: Perspectives on Emptiness in Modern History. Londres: University of London Press.

Cervera Molina, A. E. (2015). Todo es cuestión de enfoque: de Piratas a Settlers. La construcción simbólica de la península de Yucatán como una isla continental. Una aproximación a la creación del discurso histórico. En M. Shrimpton Masson \& O. Ortega (eds.), Interrogando los límites del texto. Ensayos de crítica literaria (pp. 2138). Mérida: Universidad Autónoma de Yucatán.

Colli, G. (2012). Gorgias y Parménides. México: Sexto piso.

Dampier, W. (2004). Dos viajes a Campeche, con el facsimilar de la edición inglesa de 1705. $2^{\mathrm{a}}$ ed. México: Porrúa.

Descola, P. (2012). Más allá de la naturaleza y de la cultura. Buenos Aires: Amorrortu.

Giménez, G. \& Héau Lambert, K. (2007). El desierto como territorio, paisaje y referente de identidad, Culturales, 3(5), 7-42.

Harley, J. B. (2005). La nueva naturaleza de los mapas. Ensayos sobre la historia de la cartografía. México: Fondo de Cultura Económica.

Hiernaux, D. \& Lindón, A. (1993). El concepto de espacio y el análisis regional. Revista Secuencia, 25, 89-110.

Latour, B. (1993). We Have Never Been Modern. Massachusetts: Harvard University Press. 
Macías Zapata, G. A. (2004). El vacío imaginario. Geopolítica de la ocupación territorial en el Caribe oriental mexicano. México: Ciesas.

Nogué, J. (2012). Intervención en imaginarios paisajísticos y creación de identidades territoriales. En A. Lindón \& D. Hiernaux (eds.), Geografías de lo imaginario (pp. 129-139). México: Universidad Autónoma Metropolitana, Anthropos.

Rio Fernandes, J. A., Savério Sposito, E. \& Trinca Fighera, D. (Eds.). (2015). Diccionario de geografía aplicada y profesional. Terminología de análisis, planificación y gestión del territorio. León: Universidad de León. Recuperado de http://www.uv.es/ javier/ index_archivos/Diccionario_Geografia Aplicada.pdf.

Salgari, E. (2004). La reina de los caribes. Recuperado de http://www.biblioteca.org.ar/ libros/155502.pdf.

Santos, M. (1996). A natureza do espaço. Técnica e tempo. Razão e emoção. São Paulo: Editora Hucite.

Sauer, C. O. (1956). The Education of a Geographer. Annals of the Association of American Geographers, 46(3), 287-299.

Tuan, Y-F. 1979. Space and Place: Humanistic Perspective. En S. Gale \& G. Olsson (eds.), Philosophy in Geography. Theory and Decision Library. Vol 20. Dordrecht: springer.

Turner, V. W. (1980). La selva de los símbolos. México: Siglo XXI.

Van Gennep, A. (2008). Los ritos de paso. España: Alianza Editorial.

Volpi, F. (2005). Gorgias de Leontinos. En Enciclopedia de obras de filosofía. Vol. X. Barcelona: Herder. 